is anything final or absolute in the present form and traditional methods of the university, and in not seeing that if only a profound change in all our cultural habits will save our civilization, we must plan and effect that change". "But here we must transcend the limitations of our own humanist tradition : for the first step toward world co-operation must rest on our realization that the humanities are not a special creation of Western civilization. . . . Unless we are humble enough to learn from all these sources", humanists will miss the opportunity of "carving out a much larger and much more significant place for themselves than they have ever occupied before".

David Mitrany.

\section{THE EXPANDING LIBRARY}

The Scholar and the Future of the Research Library A Problem and its Solution. By Fremont Rider. Pp. xv+236. (New York: Hadham Press, 1944.) 4 dollars.

THE growth of American research libraries, averaged together, according to figures quoted by Mr. Fremont Rider, shows a doubling at almost exactly sixteen-year intervals, and there seems no good reason for believing that the rate of growth will be seriously checked for many years to come. If unchecked, the figures for some of America's largest libraries will become astronomical. Though, for a variety of reasons, the rate of growth of British libraries is not equally rapid, there is much of value and interest to be found in Mr. Rider's examination of the problems involved and in the suggested solution.

In the first part of the book, Mr. Rider recapitulates various current methods of reducing the growth of research libraries, and shows why they cannot be wholly satisfactory. $\mathrm{He}$ is entirely concerned with the problem of the research library serving the more advanced type of reader; comparable, in fact, to British national libraries such as the British Museum or the Bodleian. In such libraries it is an axiom that no class of material can be discarded with impunity. Even the trivia of to-day may prove valuable in relation to sociological or biographical research a century later. The scholar's needs are casual, but they are also urgent and unpredictable. In a satisfactory service he expects, within reason, to have his material available for quick consultation.

Mr. Fremont Rider's solution lies in 'micro-cards'. By this term he means the reproduction, in microprint, of the text of the book or paper itself, on the back of a catalogue card. The face of the card would show the catalogue entry and an abstract of the work, in print of ordinary size. A careful choice of the form of the catalogue entry would enable the same cards to be used for author, title or subject catalogues, thus doing away with the need for further copying or additions by the subscribing libraries. Mr. Rider specifically suggests the use of the 'Readex' process, by which it is possible to print 100-250 pages of a book on a standard library card, but other adaptations of micro-photography are also possible. The resulting economy in space and cost is obvious.

The second half of the book deals with the microcards, their format, publication and uses, and with the problems of copyright. Mr. Rider stresses the fact that success in the use of micro-cards will depend largely upon an agreed format for the catalogue entry and subject headings, since interchangeability of cards among the subscribing libraries is an absolute necessity. It is therefore of great importance that the cards should be made, in the first place, by bibliographical experts. Mr. Rider recommends an extension of the division-of-fields suggestions already put forward by the Metcalf Committee. According to these proposals, each of the co-operating libraries would select its own particular sphere of interest and would endeavour to collect all research material pertaining to this field. Mr. Rider suggests that each of the co-operating libraries, thus having at hand all data relevant to its own field, would be in the best position to draw up the most accurate catalogue entry and subject classification for such material. Each library should therefore issue the micro-cards for works within its own field, receiving in turn micro-cards from other libraries specializing in other fields.

Objections to the schemes proposed by Mr. Rider could be immediately suggested, but much remains that is worthy of close attention. Micro-print, as distinct from micro-film, is still in the early stages of evolution, and reader-machines are in short supply. It may, however, reasonably be anticipated that supply will follow demand and that improved technique and equipment will rapidly be developed.

The method of combining the legible catalogue entry with the actual text of the original eliminates many of the disadvantages of micro-film and has much to recommend it as a self-contained and rapid means of access to reference works. Those who have felt that the potential value of micro-photography as an aid to the solution of library problems has not yet been fully utilized should draw inspiration from this book.

E. M. R. Ditmas.

\section{BRITISH PLANT DISEASES}

\section{List of Common British Plant Diseases}

Compiled by the Plant Pathology Committee of the British Mycological Society. Pp. 61. (Cambridge : At the University Press, 1944.) 5s. net.

SO far back as 1928 the British Mycological Society $S$ decided to appoint a committee of men of science interested in plant diseases, their object being to compile a list of the more important diseases of British crop and ornamental plants and to suggest for each disease a single selected common name. It was hoped to encourage the use of these selected names so that uniformity in the naming of plant diseases could be achieved at least in the British Isles. Many people dealing with plants must be aware that the same disease of a particular plant may be known by several common names according to the locality, and furthermore that a name is often quite unsuitable for describing the disease to which it refers.

The Committee produced its first list in 1929 in the Transactions of the British. Mycological Society, 14, and further improved on this by publishing a second edition of the list in book form in 1935 .

It has now produced in book form a third edition, with various emendations and additions, printed as before in two parallel columns, on the left the name of the host plant with, under it, the recommended common names of its diseases, and on the right the scientific name of the parasite causing the disease. In the case of diseases not caused by 